\title{
A systematic review and meta-analysis of the prevalence of bipolar disorder among homeless people
}

\author{
Getinet Ayano ${ }^{1,2^{*}}$ (D), Shegaye Shumet ${ }^{3}$, Getachew Tesfaw ${ }^{3}$ and Light Tsegay ${ }^{4}$
}

\begin{abstract}
Background: Bipolar disorder (BD) is a common severe mental disorder among homeless people and is associated with an increased risk of disability and mortality from suicide, medical causes (including HIV/AIDS, hepatitis infection, hypertension, and tuberculosis), as well as substance use disorders. However, a systematic synthesis of the existing evidence on the subject is lacking. To fill this gap in the literature, this study aimed to carry out systematic review and meta-analysis to determine the consolidated prevalence of BD among homeless people.

Methods: In this systematic review and meta-analysis, we searched Embase, PubMed, and Scopus to identify pertinent studies that reported the prevalence of BD among homeless people in March 2019. Random effect metaanalysis was employed to pool data from the eligible studies. Subgroup and sensitivity analysis was conducted and Cochran's Q- and the $I^{2}$ test were utilized to quantify heterogeneity. Publication bias was assessed by using Egger's test and visual inspection of the symmetry in funnel plots.

Results: Of 3236 studies identified, 10 studies with 4300 homeless individuals were included in the final analysis. Among the 10 studies, five studies used the Diagnostic Statistical Manual of Mental disorders (DSM), three studies used Mini-International Neuropsychiatric Interview (MINI), one study used Schedule for Clinical Assessment of Neuropsychiatry (SCAN), and one study used Composite International Neuropsychiatric Interview (CIDI) to assess BD among homeless individuals. Based on the results of the random effect model, the prevalence of BD among homeless people was $11.4 \%$ (95\% Cl; 7.5-16.9). The prevalence of BD was $10.0 \%(95 \% \mathrm{Cl} ; 3.1-27.9)$ in Europe and it was $13.2 \%$ (95\% Cl; 8.9-19.3) in other countries. Moreover, the prevalence of BD was $11.5 \%$ (95\% Cl; 5.5-22.3) for studies that used DSM to assess BD and it was $11.0 \%(95 \% \mathrm{Cl} ; 6.1-19.2)$ for studies that used other instruments (MINI, SCAN, and CIDI).
\end{abstract}

Conclusion: Our meta-analysis demonstrated that BD is highly prevalent among homeless individuals, underlying the importance of early screening and targeted interventions for BD among homeless individuals.

Keywords: Prevalence, Bipolar disorder, Homeless, Systematic review, Meta-analysis

\footnotetext{
* Correspondence: babiget2015@gmail.com

${ }^{1}$ Research and Training Department, Amanuel Mental Specialized Hospital,

Addis Ababa, Ethiopia

${ }^{2}$ School of Public Health, Curtin University, Perth, WA, Australia

Full list of author information is available at the end of the article
}

\section{$\triangle B M C$}

(c) The Author(s). 2020 Open Access This article is licensed under a Creative Commons Attribution 4.0 International License, which permits use, sharing, adaptation, distribution and reproduction in any medium or format, as long as you give appropriate credit to the original author(s) and the source, provide a link to the Creative Commons licence, and indicate if changes were made. The images or other third party material in this article are included in the article's Creative Commons licence, unless indicated otherwise in a credit line to the material. If material is not included in the article's Creative Commons licence and your intended use is not permitted by statutory regulation or exceeds the permitted use, you will need to obtain permission directly from the copyright holder. To view a copy of this licence, visit http://creativecommons.org/licenses/by/4.0/ The Creative Commons Public Domain Dedication waiver (http://creativecommons.org/publicdomain/zero/1.0/) applies to the data made available in this article, unless otherwise stated in a credit line to the data. 


\section{Background}

According to a report from Yale University, around 150 million people, or roughly $2 \%$ of the global population were classified as homeless, and as many as 1.6 billion people (20\% of the world population) lacked adequate housing [1]. Among the many causes of homelessness- mental illness, sexual assault, poverty, domestic violence, unemployment, addictions, a critical shortage of affordable housing, social isolations, family breakdown, adverse childhood experiences, and financial difficulties were reported as the most common factors in different studies [2-6].

Numerous studies have reported a higher prevalence of psychiatric disorders among homeless people. The diagnosis of psychiatric disorders among homeless people ranged from 25 to $50 \%$ depending on the studies [7-10]. The prevalence rates are reported as high as $92 \%$ among those who are street homeless [11]. The diagnoses of psychiatric disorders among homeless people associated with an elevated risk of mortality from suicide and general medical [12-15] and drug-related causes [16].

Bipolar disorder (BD) is one of the most common mental disorders among homeless people that is associated with an increased risk of disability, substance/drug abuse as well as mortality from suicide, and medical causes (including HIV/AIDS, hepatitis infection, hypertension, and tuberculosis), as well as substance use disorders $[12-14,17,18]$. Bipolar disorder is estimated to affect 2.41 to $42.42 \%$ of the homeless people depending on the studies [17-22]. The consequences of BD among homeless people may be severe and far-reaching; it negatively affects the person experiencing $\mathrm{BD}$ as well as their family $[12,16,23,24]$.

Even though, the existing epidemiologic evidence show a greater burden of $\mathrm{BD}$ among homeless people coupled with its negative consequence associated with a greater risk of mortality, higher medical comorbidity, increased substance use, risky behaviors, disability and poor quality of life for the affected people, to date there are no systematic review and meta-analysis that reported the pooled prevalence of BD among homeless people. Thus, the objective of this systematic review and meta-analysis is to estimate the prevalence of $\mathrm{BD}$ among the homeless by pooling the existing data on the prevalence of $\mathrm{BD}$ among the homeless population and provide a recommendation for future research and clinical practice.

\section{Methods}

\section{Research design and method}

The PRISMA (Preferred Reporting Items for Systematic Reviews and Meta-Analyses) guidelines [25] was used to conduct this systematic review and meta-analysis. We used a predesigned protocol for searching, data abstraction, inclusion-exclusion criteria, quality evaluation, as well as data synthesis and analysis.

\section{Data source and selection process}

An extensive search of three electronic databases (Embase, PubMed, and Scopus) was conducted in March 2019. We employed our search in PubMed using the following terms and keywords: ((("bipolar disorder" $[\mathrm{MeSH}$ Terms] OR ("bipolar"[All Fields] AND "disorder"[All Fields]) OR "bipolar disorder"[All Fields]) OR ("mental disorders"[MeSH Terms] OR ("mental"[All Fields] AND "disorders"[All Fields]) OR "mental disorders"[All Fields] OR ("mental" [All Fields] AND "illness"[All Fields]) OR "mental illness"[All Fields]) OR ("mental disorders"[MeSH Terms] OR ("mental"[All Fields] AND "disorder$\mathrm{s}$ "[All Fields]) OR "mental disorders"[All Fields] OR ("psychiatric"[All Fields] AND "disorder"[All Fields]) OR "psychiatric disorder"[All Fields])) AND (("epidemiology"[Subheading] OR "epidemiology"[All Fields] OR "prevalence"[All Fields] OR "prevalence"[MeSH Terms]) OR magnitude [All Fields] OR ("epidemiology"[Subheading] OR "epidemiology" [All Fields] OR "epidemiology" [MeSH Terms]))) AND (("homeless persons"[MeSH Terms] OR ("homeless"[All Fields] AND "persons"[All Fields]) OR "homeless persons"[All Fields] OR "homeless"[All Fields]) OR ("homeless persons"[MeSH Terms] OR ("homeless"[All Fields] AND "persons"[All Fields]) OR "homeless persons"[All Fields] OR "homelessness"[All Fields])). For Embase and Scopus database searching we applied specific-subjects headings suitable for each database. We also conducted a manual search of the reference lists of eligible articles to supplement the electronic database search.

\section{Inclusion and exclusion criteria}

To be included in this systematic review and metaanalysis studies had to satisfy the following criteria: (1) observation study in design was used to conduct the study (cross-sectional, case-control or cohort studies); (2) the source population was homeless people (conducted among homeless people); (3) measured the prevalence of bipolar disorders or data to calculate the prevalence was reported; (4), were a primary study in type. Additionally, studies were not excluded based on the type of homelessness (studies involving any type of homelessness were included without restriction). Excluded were reviews, book reviews, commentaries, and conference presentations.

\section{Selection of studies for the inclusion in the systematic review and meta-analysis}

The corresponding author (GA) identified studies and subsequently screened them using their titles as well as abstract against the inclusion and exclusion criteria. Full-text studies were selected for further valuation by the author. This author further evaluated the full text of each article and consequently retained those full-text 
articles to be included in the present systematic review and meta-analysis.

\section{Methods for data extraction and quality assessment} Two reviewers (SS and GT), independently conducted manual data extraction from the eligible articles. As suggested by PRISMA guidelines [25], we utilized predefined data extraction to abstract pertinent data from the eligible studies. The following information was extracted from all eligible full-text articles: the name of authors, tools used, location, study design and setting, a sample size, year of publication, and prevalence of BD. A modified version of the Newcastle-Ottawa Scale (NOS) was used to evaluate the quality of eligible articles [26].

\section{Data synthesis and analysis}

The meta-analysis was conducted by using comprehensive meta-analysis software version 3. A random-effect meta-analysis was used to pool prevalence data from the included studies. Q statistic and $\mathrm{I}^{2}$ statistics were employed to evaluate the heterogeneity [27]. The magnitude of heterogeneity between studies was evaluated by $\mathrm{I}^{2}$ statistics [27] and values of 25, 50 and $75 \%$ denoted low, medium and high, respectively [28]. The instrument used to measure $\mathrm{BD}$, the geographic location of the study, and the quality of the eligible articles was used as a moderator to quantify the possible source of heterogeneity between the studies. The evidence of publication bias was determined by using a funnel plot and Egger's regression tests.

\section{Results}

\section{Identification of studies}

A total of 3236 eligible articles were identified by our electronic databases and manual searches. After title and abstract verification and eliminating duplicate articles, 30 articles remained for full-text screening. Of these, 20 were excluded, as they did not meet the inclusion criteria. The major reasons for the exclusion include: (1) the study population was not on homeless $(n=8)$, (2) not measured prevalence of bipolar disorders $(n=8),(3)$ reviews $(n=2)$, and (4) duplicate $(\mathrm{n}=2)$. Thus, a fulltext of 10 studies, which satisfied the eligibility criteria, were included in the final analysis (Fig. 1, supplementary files 1 and 2).

\section{Characteristics of included studies}

Table 1 summarizes the characteristics of the included studies. A total of 10 studies were included in the final systematic review and meta-analysis. The included articles were performed in five countries representing a total of 4300 homeless people. From the total, three studies were conducted in Canada [31-33], two studies were conducted in the USA $[29,30]$, two studies in Germany
[20, 21], one in Ireland [33], one in Brazil [35], and one was conducted in France [22]. The included studies were published between 2001 and 2017, with the sample size ranging between 38 participants in Ireland and 2088 participants in Canada. Among the 10 studies, five studies used the Diagnostic Statistical Manual of Mental disorders (DSM), three studies used Mini-International Neuropsychiatric Interview (MINI), one study used Schedule for Clinical Assessment of Neuropsychiatry (SCAN), and one study used Composite International Neuropsychiatric Interview (CIDI) to assess BD among homeless individuals.

\section{Quality of the included studies}

The quality of the eligible studies was evaluated by using the NOS with modification. Among the total, five articles found to be high quality (NOS score 8 and above), three were low quality (NOS score less than or equal to 5), and two were moderate quality studies (NOS score between 6 and 7 inclusive). The results show that most of the included studies had no significant risk of bias in the selection of the participants, as well as ascertainment of the outcome. Also, our sensitivity and meta-regression analysis revealed that the quality of the studies had no significant impacts on the over prevalence estimates of $\mathrm{BD}$ among homeless individuals (Supplementary file 3).

\section{The prevalence of BD among homeless people (meta- analysis)}

The pooled prevalence estimate of BD among homeless people was $11.4 \%$ (95\% CI; 7.5-16.9) with significant heterogeneity between the studies $\left(I^{2}=93.9 \% ; p<0.001\right)$. This pooled prevalence of $\mathrm{BD}$ among homeless people was yielded based on all 10 included studies and is illustrated by the forest plot in Fig. 2. The reported pooled prevalence was based on the random-effects model that we employed to account for the existing heterogeneity.

\section{Subgroup analysis The prevalence of BD among homeless people by country (continent)}

In this systematic review and meta-analysis, we have conducted a subgroup analysis by using the country/ continent as a moderator (studies conducted in Europe vs. other countries). For this analysis, we included four studies from Europe [20-22, 33], three studies from Canada [31-33], two studies from the USA [29, 30], and one study from Brazil [35]. The prevalence of BD was $10.0 \%$ (95\% CI; 3.1-27.9) in Europe and it was $13.2 \%$ (95\% CI; 8.9-19.3) in other countries. Significant heterogeneity was found for both studies conducted in Europe $\left(I^{2}=94.5 \%, p<0.0001\right)$ as well as studies conducted in other countries $\left(I^{2}=94.1 \%, p<0.0001\right)$ (See Table 2$)$. 


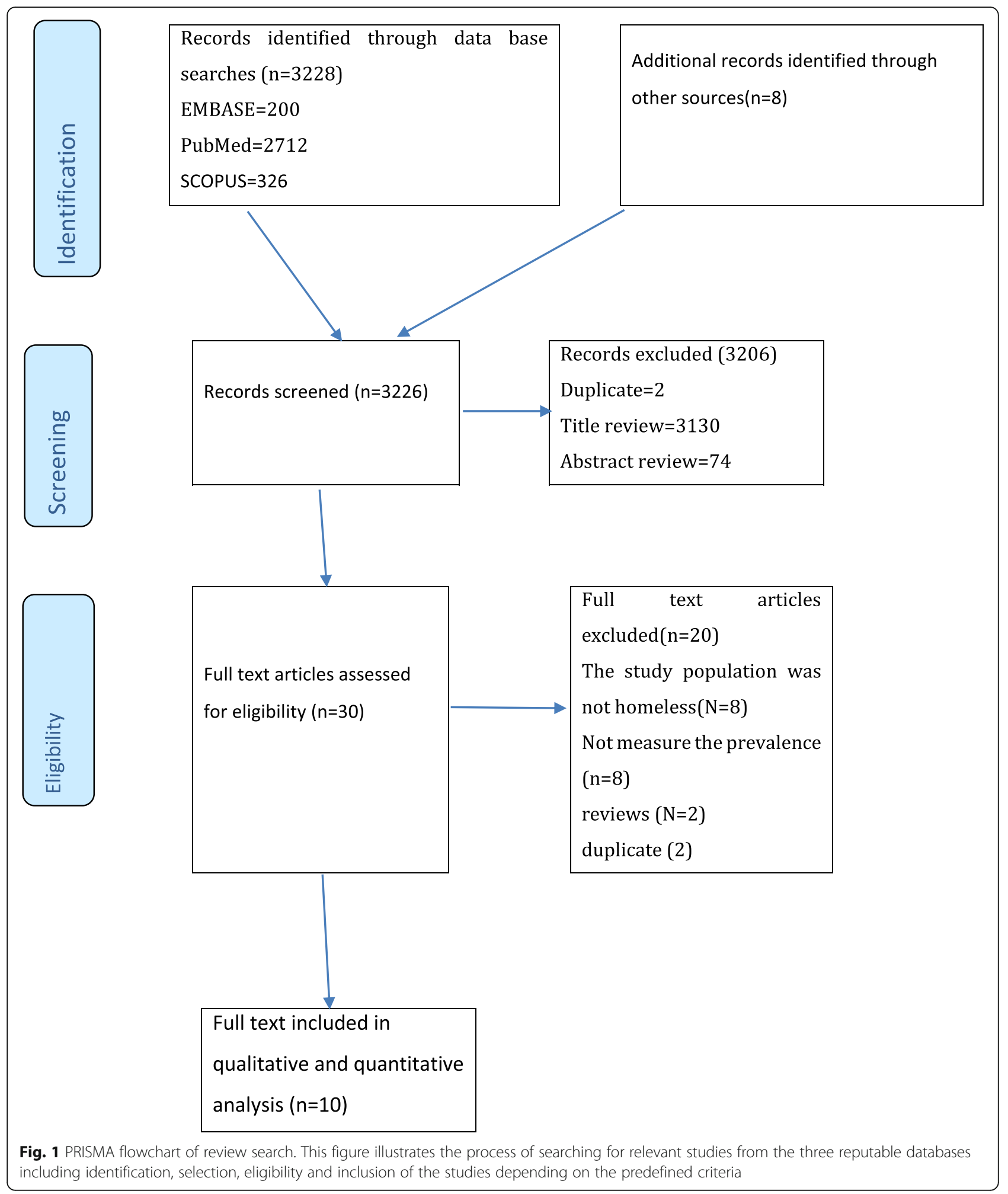

\section{Subgroup analysis of the prevalence of BD among} homeless people by the instrument used

We also conducted a stratified analysis by the type of instrument used to measure $\mathrm{BD}$ among the homeless people using a random effect model. The prevalence of
BD was $11.5 \%$ (95\% CI; 5.5-22.3) for studies that used DSM to assess BD and it was $11.0 \%$ (95\% CI; 6.1-19.2) for studies that used other instruments (MINI, SCAN, and CIDI). The reported heterogeneity was significant for both studies conducted by DSM $\left(I^{2}=87.0 \%, \mathrm{p}<\right.$ 
Table 1 Distribution of studies on bipolar disorder among homeless people based on study year name, year of publication, sample size, instrument, country, and prevalence

\begin{tabular}{llllll}
\hline Author (year) (reference number) & Sample size & Tool & Country & Type of homelessness & Prevalence \\
\hline Koegel et.al. 1988 [29] & 328 & DSM & USA & 10.6\% $(n=35)$ \\
Fichter et.al. 2001 [20] & 265 & DSM & Germany & Shelter users, service users and street dwellers & $8.3 \%(n=22)$ \\
Connolly et.al. 2008 [30] & 60 & DSM & USA & $5 \%(n=3)$ \\
Noel et.al. 2016 [31] & 497 & DSM & Canada & $N=19 \%(N=97)$ \\
Topolovec-Vranic et al. 2017 [32] & 2088 & MINI) & Canada & $12.6 \%(N=263)$ \\
Prinsloo et.al. 2012 [33] & 38 & DSM & Ireland & $5.3 \%(n=2)$ \\
Kovess et.al. 1999 [22] & 715 & CIDI & France & $3.6 \%(n=26)$ \\
Greifenhagen et.al. 1997 [21] & 32 & DSM & Germen & $44 \%(n=14)$ \\
Strehlua et.al. 2012 [34] & 193 & MINI & Canada & $28 \%(n=53)$ \\
Heckert et.al. 1999 [35] & 83 & SCAN & Brazil & $2.41 \%(n=2)$ \\
\hline
\end{tabular}

$0.0001)$ and other instruments $\left(I^{2}=96.1 \%, p<0.001\right)$ (See Table 2).

\section{Subgroup analysis of the prevalence of BD among homeless people by the quality of studies}

Furthermore, we also conducted a subgroup analysis by the quality of the eligible studies. The pooled prevalence of $\mathrm{BD}$ was found to be $9.9 \%$ (95\% CI, 6.2-15.3) for highquality studies and the pooled prevalence for both low and moderate-quality studies combined was $11.8 \%(95 \%$ CI, 4.3-28.6).

The reported heterogeneity was significant for high $\left(I^{2}=94.4 ; \mathrm{p}<0.001\right)$ as well as low and moderate $\left(I^{2}=\right.$ 88.4; $\mathrm{p}<0.001$ ) quality studies. (See Table 2).

\section{Subgroup analysis based on the sample size of the study}

The prevalence of BD was $10.1 \%$ (95\% CI 5.1-19.1) for studies that included a sample of 400 and above homeless participants and it was $11.5 \%$ (95\% CI; 5.8-21.2) for studies that included less than 400 homeless participants (See Table 2).

\section{Sensitivity analysis}

Sensitivity analysis was performed according to the country of study (origin of the study), the instrument used to measure $\mathrm{BD}$, and the quality of the included studies to further explore the possible source of heterogeneity in the analysis of the prevalence of $\mathrm{BD}$ among homeless people. Our sensitivity analysis demonstrated that the prevalence of $\mathrm{BD}$ was slightly lower in Europe (10.0\%) when compared with other countries (13.2\%), although the variation was not statistically significant $(P=0.635)$ (see Table 2).

Moreover, we performed a sensitivity analysis based on the tools used to quantify BD among homeless people as a moderator. The findings demonstrated that the prevalence of $\mathrm{BD}$ among the homeless individuals

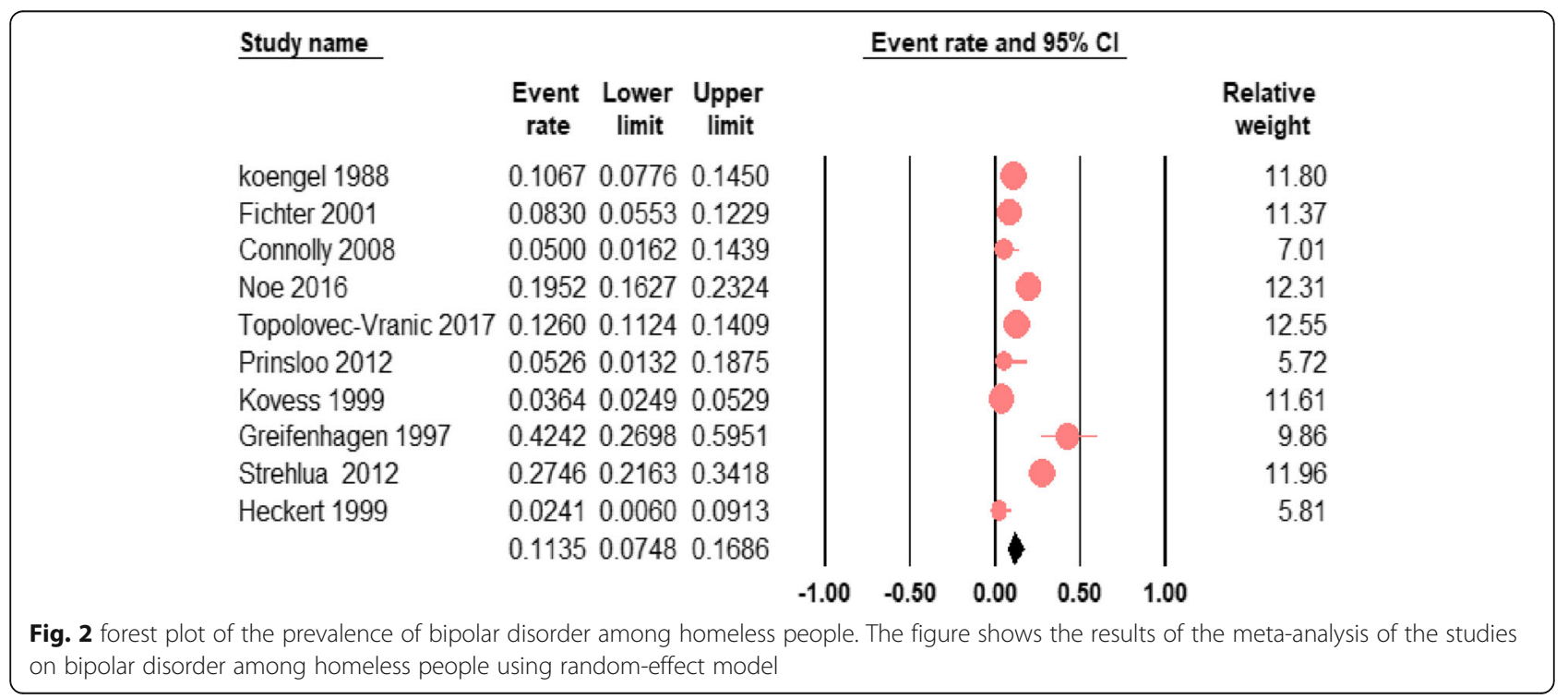


Table 2 Subgroup and sensitivity analysis of the prevalence of bipolar disorder among homeless participants

\begin{tabular}{|c|c|c|c|c|c|c|}
\hline \multirow[t]{2}{*}{ Subgroup } & \multirow{2}{*}{$\begin{array}{l}\text { Number } \\
\text { of } \\
\text { studies }\end{array}$} & \multicolumn{2}{|l|}{ Estimates } & \multicolumn{2}{|c|}{ Heterogeneity across the studies } & \multirow[t]{2}{*}{ Heterogeneity between groups ( $P$-value) } \\
\hline & & Prevalence (\%) & 95\% Confidence interval & $\overline{I^{2}(\%)}$ & $P$-value & \\
\hline \multicolumn{7}{|c|}{ Country (continent) } \\
\hline Europe & 4 & 10.0 & $3.1-27.9$ & 94.5 & $<00010$ & 0.635 \\
\hline Others & 6 & 13.2 & $8.9-19.3$ & 94.1 & $<0001$ & \\
\hline \multicolumn{7}{|l|}{ Instrument used } \\
\hline DSM & 5 & 11.5 & $5.5-22.3$ & 87.0 & $<0.0001$ & 0.926 \\
\hline Other & 5 & 11.0 & $6.1-19.2$ & 96.1 & $<0.0001$ & \\
\hline \multicolumn{7}{|c|}{ Quality of the study } \\
\hline High & 5 & 9.9 & $6.2-15.3$ & 94.4 & $<0.0001$ & 0.743 \\
\hline Moderate and low & 5 & 11.8 & $4.3-28.6$ & 88.4 & $<0.0001$ & \\
\hline \multicolumn{7}{|l|}{ Sample size } \\
\hline 400 and above & 3 & 10.1 & $5.1-19.1$ & 97.0 & $<0001$ & 0.791 \\
\hline Below 400 & 7 & 11.45 & $5.8-21.2$ & 91.0 & $<0001$ & \\
\hline
\end{tabular}

was comparable between the studies conducted using the DSM and other instruments (see Table 2).

We also conducted a sensitivity analysis by using the quality of the included studies as a moderator. This analysis showed that the estimated prevalence of $\mathrm{BD}$ was found to be higher for low quality and moderate-quality studies $(16.7 \%)$ as compared to high-quality studies (9.9\%), although the difference was not statistically significant $(P=0.743)$ (see Table 2).

Furthermore, our sensitivity analysis revealed that the prevalence of $\mathrm{BD}$ among the homeless individuals did not significantly vary based on the sample size used to estimate the prevalence of BD among the participants (see Table 2).

Furthermore, to confirm whether the results of our final meta-analyses were heavily affected by study with greater relative weight, we performed a sensitivity analysis by removing a study with a higher relative weight [34] and the results revealed no significant variation in our final results. The prevalence was 10.0\% (95\% CI 6.515.1) after excluding a study with a larger relative weight [32].

\section{Meta-regression}

Firstly, we have performed a univariate regression analysis that directed the selection of the important variables to involve in the final meta-regression analysis. All independent variables with $P$-value $<0.8$ were included in the final meta-regression model as suggested by Ferrari et.al. (Ferrari et al., 2013). In the final metaregression analysis model, we quantified the impacts of sample size (400 and above and below 400), continent (country) (studies conducted in Europe and other countries), and, and the instrument used to measure depression (DSM and others). The overall proportion of variance explained by the above covariates in the final model was $8 \%\left(R^{2}=0.08 ; P\right.$ value $\left.=0.772\right)$. All three independent variables such as diagnostic instruments, sample size, as well as a continent (country) were not significant determinants for the observed difference in the prevalence of bipolar disorders among homeless individuals (Table 3 ).

\section{Publication bias}

Figure 3 demonstrates the risk of publication bias. The analysis revealed that the funnel plot was symmetric and Egger's regression tests provided no evidence of substantial publication bias for the prevalence of $\mathrm{BD}$ among the homeless people $(\mathrm{B}=-1.14, \mathrm{SE}=2.19, P$-value $=0.792)$.

\section{Discussion \\ Main findings}

To the best of our knowledge, this is the first systematic review and meta-analysis that assessed the prevalence of $\mathrm{BD}$ among homeless people. Ten studies with a total of 4300 homeless people conducted across six countries were included in the final analysis. The findings of this systematic review indicated that the available epidemiologic evidence on the prevalence of $\mathrm{BD}$ among homeless people showed an apparent variation by the tools used to measure $\mathrm{BD}$, the study location (the origin of the study), as well as the quality of the included articles, although the variation was not statistically significant. To measure $\mathrm{BD}$, some of the articles employed screening instruments and some employed diagnostic instruments. Nine of the included studies were conducted in developed countries including 2 studies in the USA, 3 studies in Canada, and 4 studies in Europe and only one study was conducted in developing countries (Brazil). 
Table 3 Summary of the meta-regression analysis including sample size, country (continent where the study was conducted, and the quality of the studies in the model

\begin{tabular}{|c|c|c|c|c|c|c|}
\hline \multirow[t]{2}{*}{ Variables in the final model } & \multicolumn{2}{|l|}{ Univariate model } & \multirow[b]{2}{*}{$P$-value } & \multicolumn{3}{|c|}{ Multivariable model } \\
\hline & Coefficients & $95 \% \mathrm{Cl}$ & & Coefficients & $95 \% \mathrm{Cl}$ & $P$-value \\
\hline \multicolumn{7}{|l|}{ Sample size } \\
\hline $\begin{array}{l}400 \text { and above } \\
\text { Below } 400\end{array}$ & $\begin{array}{l}\text { Reference } \\
0.188\end{array}$ & $\begin{array}{l}\text { Reference } \\
-0.865-1.242\end{array}$ & $\begin{array}{l}\text { Reference } \\
0.727\end{array}$ & $\begin{array}{l}\text { Reference } \\
-0.032\end{array}$ & $\begin{array}{l}\text { Reference } \\
-1.214-1.152\end{array}$ & $\begin{array}{l}\text { Reference } \\
0.958\end{array}$ \\
\hline \multicolumn{7}{|l|}{ Country (continent) } \\
\hline $\begin{array}{l}\text { Europe } \\
\text { Others }\end{array}$ & $\begin{array}{l}\text { Reference } \\
0.252\end{array}$ & $\begin{array}{l}\text { Reference } \\
-0.659-1.163\end{array}$ & $\begin{array}{l}\text { Reference } \\
0.588\end{array}$ & $\begin{array}{l}\text { Reference } \\
0.249\end{array}$ & $\begin{array}{l}\text { Reference } \\
-0.670-1.168\end{array}$ & $\begin{array}{l}\text { Reference } \\
0.595\end{array}$ \\
\hline \multicolumn{7}{|l|}{ Quality of studies } \\
\hline $\begin{array}{l}\text { High } \\
\text { Low/moderate }\end{array}$ & Reference 0.421 & $\begin{array}{l}\text { Reference } \\
-0.794-1.321\end{array}$ & $\begin{array}{l}\text { Reference } \\
0.326\end{array}$ & $\begin{array}{l}\text { Reference } \\
0.438\end{array}$ & $\begin{array}{l}\text { Reference } \\
-0.721-1.597\end{array}$ & $\begin{array}{l}\text { Reference } \\
0.459\end{array}$ \\
\hline
\end{tabular}

Test of the model (multivariable model): $\mathrm{R}^{2}=0.08 ; P$-value $=0.772$

This meta-analysis showed that the pooled prevalence of $\mathrm{BD}$ among homeless people was $11.4 \%$. This result is remarkably higher (11.35-fold higher) than the reported prevalence of $\mathrm{BD}$ among the general population [36]. For example, a recent systematic review and metaanalysis conducted by Clement et al. found that the lifetime prevalence of bipolar disorders was found to be $1 \%$ [36], whereas, the reported prevalence ranges from 1 to $2.4 \%$ depending on the studies [36-39]. The possible reasons for the higher prevalence of $\mathrm{BD}$ among the homeless could be due to the greater prevalence rates of serious medical conditions including tuberculosis, HIV/ AIDS and other medical conditions among the homeless people as compared to the reported prevalence in the general population [23, 40, 41], which in turn are associated with increased risks of bipolar and other psychiatric disorders in affected individuals [42-44]. The other possible reason for the observed variation in the prevalence of $\mathrm{BD}$ may be due to homeless people are more likely to experience traumatic events, such as physical and sexual abuse, which has been associated with the onset of a manic episode, earlier episodes, as well as early onset of bipolar illness in a risky group [45-51]. Another possible reason for a higher prevalence of $\mathrm{BD}$ among the homeless in the current study may be due to the remarkably greater prevalence of psychiatric and substance use

\section{Funnel Plot of Standard Error by Logit event rate}

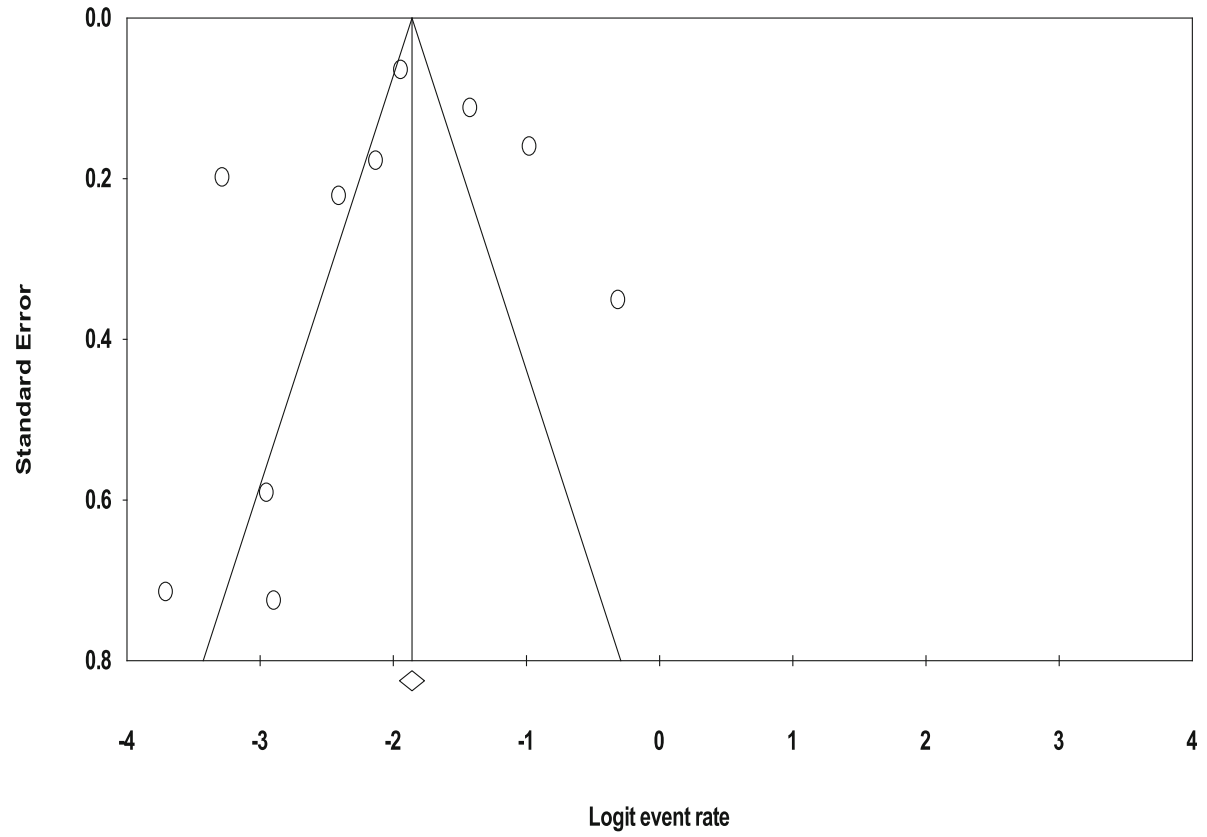

Fig. 3 Publication bias for bipolar disorders among homeless people. Funnel plot of the risk of publication bias for the prevalence of BD among the homeless individuals 
disorders among homeless people such as depression, anxiety, psychosis, personality, and alcohol use disorders among homeless people as compared to the general populations [11, 29, 52, 53]. For example, a recent nationalwide study conducted in Canada in 2018 found that $36.8 \%$ of homeless people with alcohol and substance use disorders (ASD) had comorbid BD [54]. Another study also showed that substance use disorders are common among homeless people with $\mathrm{BD}$ as compared to schizophrenia spectrum (SS) disorders and substance use problems including alcohol, cannabis, cocaine, and opiates were significantly linked with higher risks of bipolar disorders among the homeless study participants [55].

In our subgroup and sensitivity analysis, we found that the prevalence of $\mathrm{BD}$ was slightly lower in Europe (10.0\%) when compared with other countries (13.2\%), although the variation was not statistically significant $(P=0.635)$. We observed a wide variation in the prevalence of $\mathrm{BD}$ among homeless individuals ranging from $2.41 \%$ in Brazil to $44 \%$ in Germany. Additionally, among the three studies conducted in Canada, two of them reported a considerably higher prevalence of BD (above $20 \%)$ when compared with the pooled prevalence estimates (11.4\%). There is a range of explanations for the observed differences in the prevalence of $\mathrm{BD}$ among homeless people across the countries. First, the methodologic difference including the instruments used to measure BD across the included studies is the possible reason for the observed remarkable variations. For example, in all the three studies conducted in Canada, BD among homeless people was measured by a screening tool (MINI) and studies conducted in other countries have used DSM, SCAN or CIDI. Second, the differences in the prevalence of the possible factors elevating the risk of BD among vulnerable groups such as physical, psychological, and sexual trauma's, and other traumatic events and disasters, as well as serious medical conditions across the countries, are the other possible reasons for the observed variation in the prevalence of BD. Finally, the difference in the characteristics of the participants in the included studies could be the other possible reasons for the observed variation in the prevalence of BD across the countries. For instance, one of the studies conducted in Canada include homeless participants who had a history of traumatic brain injuries and in another study, the majority of homeless participants had comorbid other mental and substance use disorders [31-33], which possibly contributed to the observed high prevalence of BD in Canada. Our sensitivity analysis based on country (continent) revealed that the observed difference across the countries was not statistically significant (i.e. occurred by chance) $(P=0.635)$.

\section{Difference between the studies included in systematic review and meta-analysis}

In the current review, we found significant heterogeneity between the studies which may be due to the location of the study (the origin of the study), the tools used to measure $\mathrm{BD}$, the quality of the involved articles, and the study participants differed on numerous characteristics. However, our meta-regression analysis revealed that all three independent variables such as diagnostic instruments, sample size, as well as a continent (country) were not significant determinants for the observed difference in the prevalence of bipolar disorders among homeless individuals. We also found a variation in the prevalence of $\mathrm{BD}$ among the homeless people by the countries where the studies were conducted as well as the qualities of the included studies in the meta-analysis, although the observed variation was not statistically significant. To account for the observed heterogeneity across the studies, we have used a random effect meta-analysis where summary effect estimates are more conservative than fixed effect summaries in meta-analysis.

\section{Strength and limitations}

The current review had several strengths: (1) the abstraction of data and quality assessment were conducted by two independent investigators to reduce the probable evaluator bias; (2) performing a subgroup, sensitivity, as well as meta-regression analysis depending on the origin of the study, the instruments used to estimate BD, as well as the quality of the studies, detect the possible risk of bias.

Several limitations of this systematic review and metaanalysis should be considered: First, in the present review, the vast majority of the studies included the final analysis were conducted in developed countries $(90 \%$, $n=9$ ). Therefore, the reported prevalence of BD among homeless people may not represent the existing true prevalence of the disorder in developing countries. Second, a small number of studies were involved in our subgroup as well as sensitivity analysis, which may reduce the precision of the estimate. Third, we observed a remarkable heterogeneity across the studies. Fourth, the selection of studies by one reviewer (GA) is the other limitation of the study. This is because evidence suggests that using a second reviewer in the entire process can increase the number of studies to be included in the final reviews (reduce the probability of missing relevant studies) [56]. In fact, this is not a major concern in our meta-analysis since our publication bias analysis revealed no significant bias or small study effect $(\mathrm{B}=-1.14, \mathrm{SE}=2.19, P$-value $=0.792)$, indicating the effects of missed studies (if any) were not significant. 


\section{The implication of the findings for future research and clinical practice}

The present systematic review has some implication for the future research and clinical practice; (1), the metaanalysis resulted a higher prevalence of $\mathrm{BD}$ among homeless people as compared to the reported prevalence in the general population, which strongly emphasize the need of further studies evaluating the possible contributing factors for this prevalence as well as better preventions and treatment strategies for this population group. (2), we found a few numbers of studies that estimated the prevalence of BD in developing countries. So, further studies are required to confirm and strengthen our findings. (3), most of the studies conducted in the past several years were focused on the mental health of adult homeless people, so that studies focusing on youth homeless people are strongly warranted.

\section{Conclusion}

In conclusion, in this review, the pooled prevalence of BD among homeless people was remarkably high (11.4\%). The prevalence of BD was $10.0 \%$ in Europe and it was $13.2 \%$ in other countries. Furthermore, the prevalence of BD was $11.5 \%$ for studies that used DSM to assess $\mathrm{BD}$ and it was $11.0 \%$ for studies that used other instruments (MINI, SCAN, and CIDI). High-quality studies aimed to determine the possible reasons for the higher prevalence of $\mathrm{BD}$ among homeless people as compared to the reported prevalence in the general population are warranted. Attention needs to be given for the mental health of homeless people and strengthening mental health services for homeless people such as the possible integration of mental health services for homeless with their medical care are recommended.

\section{Supplementary information}

Supplementary information accompanies this paper at https://doi.org/10. 1186/s12889-020-08819-x.

Additional file 1: Screenshot of document results from the three databases. This additional material shows snapshot of number of studies identified during the database search PubMed $(n=2712)$, Embase $(n=$ 200), and Scopus $(n=316)$.

Additional file 2: Excluded full text studies with reasons of exclusion. The major reasons for the exclusion includes: (a) Not measured the prevalence of bipolar disorder $(n=8)$ : (b) the study population was not homeless people $(n=8)$; (2) reviews $(n=2)$; (3) duplicate $(n=2)$.

Additional file 3. The Quality of the included studies based on the NOS quality score, a 9 point score, Score 7 and above represented good quality; 6 to 7 represented moderate quality; and 0 and 5 represented poor quality.

\section{Abbreviations}

AIDS: Acquired Immune Deficiency Syndrome; CIDI: Composite International Neuropsychiatric Interview; DSM: Diagnostic Statistical Manual of Mental disorders; HIV: Human Immune Deficiency Virus; MINI: Mini International Neuropsychiatric Interview; NOS: Newcastle-Ottawa Scale; PRISMA: Preferred Reporting Items for Systematic Reviews and Meta-Analyses; SCAN: Schedule for Clinical Assessment of Neuropsychiatry; USA: United States of America; WHO: World Health Organization

\section{Acknowledgments}

Not applicable.

\section{Authors' contributions}

The author (GA) conceptualized the study, performed database search, selected studies, conducted analyses, write-up and approval of the final manuscript. SS preformed data extraction, quality assessment, and approved the final manuscript. GT and LT were participated in discussion and consensus and approved the final manuscript. All authors have read and approved the manuscript

\section{Funding}

The authors declare that there is no funding

Availability of data and materials

All data generated or analyzed during this study are included in this article.

Ethics approval and consent to participate

Not applicable.

Consent for publication

Not applicable.

\section{Competing interests}

The authors declare that there are no competing interests.

\section{Author details}

${ }^{1}$ Research and Training Department, Amanuel Mental Specialized Hospital, Addis Ababa, Ethiopia. ${ }^{2}$ School of Public Health, Curtin University, Perth, WA, Australia. ${ }^{3}$ Department of Psychiatry, College of Medicine and Health Sciences, University of Gondar, Gondar, Ethiopia. ${ }^{4}$ Department of Psychiatric Nursing, College of Health Sciences, Axum University, Axum, Ethiopia.

Received: 11 June 2019 Accepted: 30 April 2020

Published online: 09 June 2020

\section{References}

1. Yale University. Global homelessness statistics; 2017. https://yaleglobal.yale. edu/content/cities-grow-so-do-numbers-homeless.

2. Habánik T. Mental health problems as one of the factors in the development and persistence of homelessness. Kontakt. 2018;20(2):e171-6.

3. Nishio A, Horita R, Sado T, Mizutani S, Watanabe T, Uehara R, Yamamoto M. Causes of homelessness prevalence: relationship between homelessness and disability. Psychiatry Clin Neurosci. 2017;71(3):180-8.

4. Mabhala MA, Yohannes A, Griffith M. Social conditions of becoming homelessness: qualitative analysis of life stories of homeless peoples. Int J Equity Health. 2017;16(1):150.

5. Tsai J, Rosenheck RA. Risk factors for homelessness among US veterans. Epidemiol Rev. 2015:37:177-95.

6. Caton CL, Shrout PE, Eagle PF, Opler LA, Felix A. Correlates of codisorders in homeless and never homeless indigent schizophrenic men. Psychol Med. 1994;24(3):681-8.

7. Scott J. Homelessness and mental illness. Br J Psychiatry. 1993;162:314-24.

8. Breakey WR, Fischer PJ, Kramer M, Nestadt G, Romanoski AJ, Ross A, Royall RM, Stine OC. Health and mental health problems of homeless men and women in Baltimore. Jama. 1989;262(10):1352-7.

9. Gelberg L, Linn LS. Demographic differences in health status of homeless adults. J Gen Intern Med. 1992;7(6):601-8.

10. Ayano G, Tesfaw G, Shumet S. The prevalence of schizophrenia and other psychotic disorders among homeless people: a systematic review and meta-analysis. BMC Psychiatry. 2019;19(1):370.

11. Ayano G, Assefa D, Haile K, Chaka A, Solomon H, Hagos P, Yohannis Z, Haile K, Bekana L, Agidew M, et al. Mental, neurologic, and substance use (MNS) disorders among street homeless people in Ethiopia. Ann General Psychiatry. 2017;16:40

12. Babidge NC, Buhrich N, Butler T. Mortality among homeless people with schizophrenia in Sydney, Australia: a 10-year follow-up. Acta Psychiatr Scand. 2001;103(2):105-10. 
13. Hwang SW. Mortality among men using homeless shelters in Toronto Ontario. JAMA. 2000;283(16):2152-7.

14. Prigerson HG, Desai RA, Liu-Mares W, Rosenheck RA. Suicidal ideation and suicide attempts in homeless mentally ill persons: age-specific risks of substance abuse. Soc Psychiatry Psychiatr Epidemiol. 2003;38(4):213-9.

15. Ayano G, Tsegay L, Abraha M, Yohannes K. Suicidal Ideation and Attempt among Homeless People: a Systematic Review and Meta-Analysis. Psychiatr Q. 2019;90(4):829-42.

16. Barrow SM, Herman DB, Cordova P, Struening EL. Mortality among homeless shelter residents in New York City. Am J Public Health. 1999;89(4):529-34.

17. Landefeld JC, Miaskowski C, Tieu L, Ponath C, Lee CT, Guzman D, Kushel M. Characteristics and factors associated with pain in older homeless individuals: results from the health outcomes in people experiencing homelessness in older middle age (HOPE HOME) study. J Pain. 2017;18(9):1036-45.

18. Bender K, Brown SM, Thompson SJ, Ferguson KM, Langenderfer L. Multiple victimizations before and after leaving home associated with PTSD, depression, and substance use disorder among homeless youth. Child Maltreatment. 2015;20(2):115-24.

19. Taylor KM, Sharpe L. Trauma and post-traumatic stress disorder among homeless adults in Sydney. Aust N Z J Psychiatry. 2008:42(3):206-13.

20. Fichter MM, Quadflieg N. Prevalence of mental illness in homeless men in Munich, Germany: results from a representative sample. Acta Psychiatr Scand. 2001;103(2):94-104.

21. Greifenhagen A, Fichter M. Mental illness in homeless women: an epidemiological study in Munich, Germany. Eur Arch Psychiatry Clin Neurosci. 1997;247(3):162-72.

22. Kovess V, Mangin Lazarus $C$. The prevalence of psychiatric disorders and use of care by homeless people in Paris. Soc Psychiatry Psychiatr Epidemiol. 1999:34(11):580-7.

23. Martens WH. A review of physical and mental health in homeless persons Public Health Rev. 2001;29(1):13-33.

24. North CS, Smith EM, Spitznagel EL. Violence and the homeless: an epidemiologic study of victimization and aggression. J Trauma Stress. 1994; 7(1):95-110.

25. Moher D, Shamseer L, Clarke M, Ghersi D, Liberati A, Petticrew M, Shekelle P, Stewart LA, Group P-P. Preferred reporting items for systematic review and meta-analysis protocols (PRISMA-P) 2015 statement. Syst Rev. 2015;4(1):1.

26. Stang A. Critical evaluation of the Newcastle-Ottawa scale for the assessment of the quality of nonrandomized studies in meta-analyses. Eur J Epidemiol. 2010;25(9):603-5.

27. Borenstein $M$, Hedges LV, Higgins JP, Rothstein HR. A basic introduction to fixed-effect and random-effects models for meta-analysis. Res Synth Methods. 2010;1(2):97-111.

28. Higgins JP, Thompson SG, Deeks JJ, Altman DG. Measuring inconsistency in meta-analyses. BMJ. 2003;327(7414):557-60.

29. Koegel P, Burnam MA, Farr RK. The prevalence of specific psychiatric disorders among homeless individuals in the inner city of Los Angeles. Arch Gen Psychiatry. 1988;45(12):1085-92.

30. Connolly AJ, Cobb-Richardson P, Ball SA. Personality disorders in homeless drop-in center clients. J Personal Disord. 2008;22(6):573-88.

31. Noel F, Moniruzzaman A, Somers J, Frankish J, Strehlau V, Schutz C, Krausz M. A longitudinal study of suicidal ideation among homeless, mentally ill individuals. Soc Psychiatry Psychiatr Epidemiol. 2016;51(1):107-14.

32. Topolovec-Vranic J, Schuler A, Gozdzik A, Somers J, Bourque PE, Frankish CJ, Jbilou J, Pakzad S, Palma Lazgare LI, Hwang SW. The high burden of traumatic brain injury and comorbidities amongst homeless adults with mental illness. J Psychiatr Res. 2017;87:53-60.

33. Prinsloo B, Parr C, Fenton J. Mental illness among the homeless: prevalence study in a Dublin homeless hostel. Ir J Psychol Med. 2012;29(1):22-6.

34. Strehlau V, Torchalla I, Kathy L, Schuetz C, Krausz M. Mental health, concurrent disorders, and health care utilization in homeless women. J Psychiatr Pract. 2012;18(5):349-60.

35. Heckert U, Andrade L, Alves MJ, Martins C. Lifetime prevalence of menta disorders among homeless people in a southeast city in Brazil. Eur Arch Psychiatry Clin Neurosci. 1999;249(3):150-5.

36. Clemente AS, Diniz BS, Nicolato R, Kapczinski FP, Soares JC, Firmo JO, Castro-Costa É. Bipolar disorder prevalence: a systematic review and metaanalysis of the literature. Rev Bras Psiquiatr. 2015;37(2):155-61.

37. Ferrari AJ, Baxter AJ, Whiteford HA. A systematic review of the global distribution and availability of prevalence data for bipolar disorder. J Affect Disord. 2011;134(1):1-13.
38. Merikangas KR, Jin R, He J-P, Kessler RC, Lee S, Sampson NA, Viana MC, Andrade LH, Hu C, Karam EG. Prevalence and correlates of bipolar spectrum disorder in the world mental health survey initiative. Arch Gen Psychiatry. 2011:68(3):241-51.

39. Ayano G. Bipolar Disorder: A Concise Overview of Etiology, Epidemiology Diagnosis and Management: Review of Literatures. SOJ Psychol. 2016;3(1):1-8.

40. Dias M, Gaio R, Sousa P, Abranches M, Gomes M, Oliveira O, Correia-Neves M, Ferreira E, Duarte R. Tuberculosis among the homeless: should we change the strategy? Int J Tuberculosis Lung Dis. 2017;21(3):327-32.

41. Fournier AM, Tyler R, Iwasko N, LaLota M, Shultz J, Greer PJ. Human immunodeficiency virus among the homeless in Miami: a new direction for the HIV epidemic. Am J Med. 1996:100(5):582-4.

42. Mijch AM, Judd FK, Lyketsos CG, Ellen S, Cockram A. Secondary mania in patients with HIV infection: are antiretrovirals protective? J Neuropsychiatry Clin Neurosci. 1999;11(4):475-80.

43. Lin S-L, Lin C-H, Kao W-T, Chang J-L, Tzeng D-SJJoMS. Human immunodeficiency virus-associated mania and mild neurocognitive disorder. J Med Sci. 2014;34(6):267.

44. Rowland TA, Marwaha S. Epidemiology and risk factors for bipolar disorder. Ther Adv Psychopharmacol. 2018;8(9):251-69.

45. Heerde JA, Hemphill SA. Sexual risk behaviors, sexual offenses, and sexual victimization among homeless youth: a systematic review of associations with substance use. Trauma Violence Abuse. 2016;17(5):468-89.

46. Heerde JA, Scholes-Balog KE, Hemphill SA. Associations between youth homelessness, sexual offenses, sexual victimization, and sexual risk behaviors: a systematic literature review. Arch Sex Behav. 2015;44(1):181212.

47. Petering R. Sexual risk, substance use, mental health, and trauma experiences of gang-involved homeless youth. J Adolesc. 2016;48:73-81.

48. Wenzel SL, Rhoades H, Harris T, Winetrobe H, Rice E, Henwood B. Risk behavior and access to HIV/AIDS prevention services in a community sample of homeless persons entering permanent supportive housing. AIDS Care. 2017;29(5):570-4.

49. Post RM. Transduction of psychosocial stress into the neurobiology of recurrent affective disorder. Am J Psychiatry. 1992;149(8):999.

50. Ambelas A. Psychologically stressful events in the precipitation of manic episodes. Br J Psychiatry. 1979;135(1):15-21.

51. Ramana R, Bebbington P. Social influences on bipolar affective disorders. Soc Psychiatry Psychiatr Epidemiol. 1995;30(4):152-60.

52. Fazel S, Khosla V, Doll H, Geddes J. The prevalence of mental disorders among the homeless in western countries: systematic review and metaregression analysis. PLoS Med. 2008;5(12):e225.

53. Fischer PJ, Breakey WR. The epidemiology of alcohol, drug, and mental disorders among homeless persons. Am Psychologist. 1991;46(11):1115-28.

54. Maremmani AGl, Bacciardi S, Somers JM, Nikoo M, Schütz C, Jang KL, Krausz M. Substance dependence among bipolar, unipolar depression and psychotic homeless: a Canadian National Study. Front Psychiatry. 2018:9:701.

55. Maremmani AG, Bacciardi S, Gehring ND, Cambioli L, Schutz C, Jang K, Krausz M. Substance use among homeless individuals with schizophrenia and bipolar disorder. J Nerv Ment Dis. 2017;205(3):173-7.

56. Stoll CRT, Izadi S, Fowler S, Green P, Suls J, Colditz GA. The value of a second reviewer for study selection in systematic reviews. Res Synth Methods. 2019;10(4):539-45.

\section{Publisher's Note}

Springer Nature remains neutral with regard to jurisdictional claims in published maps and institutional affiliations. 